\title{
Two Rare Cases of Familial (Mother and Daughter) Adrenocorticotropic Hormone-independent Cushing's Syndrome due to Adrenal Adenoma, as well as the Asynchronous Development of Another Contralateral Adrenal Adenoma in the Mother
}

\author{
Atsushi Ogo ${ }^{1}$, Yuka Sakaki ${ }^{1}$, Nao Hasuzawa ${ }^{1}$, Ryoko Saitou ${ }^{1}$, Yuka Matoba ${ }^{1}$, \\ Takeshi Usui ${ }^{2}$ and Mitsuhide Naruse ${ }^{2}$
}

\begin{abstract}
We herein report two cases involving a mother and daughter who presented with clinical features of Cushing's syndrome (CS) at 50 and 29 years of age, respectively, and were both found to have adrenocorticotropic hormone-independent adrenal adenoma. Furthermore, a new adenoma was detected in the contralateral adrenal gland in the mother 10 years after surgical treatment, when she presented with subclinical CS. The pathogenesis of this disorder, including the presence of unknown genetic abnormalities causing hereditary $\mathrm{CS}$, is currently poorly understood. In this report, we describe our experience with and consider the pathophysiological implications of two rare and very interesting cases of familial CS.
\end{abstract}

Key words: familial, Cushing's syndrome, adrenal adenoma, asynchronous

(Intern Med 53: 987-995, 2014)

(DOI: 10.2169/internalmedicine.53.0352)

\section{Introduction}

Cushing's syndrome (CS) is characterized by pathologically by an elevated glucocorticoid level. Causes of CS in adults include Cushing's disease (pituitary-dependent bilateral adrenal hyperplasia), ectopic adrenocorticotropic hormone (ACTH) (and corticotropin-releasing hormone) production and primary adrenal disorders (adenoma, adrenocarcinoma and nodular hyperplasia). Familial forms of CS are rare (1-3), and most reported cases have been associated with nodular adrenocortical dysplasia, which exhibits an autosomal dominant inheritance pattern. We herein report the cases of a mother and daughter who presented with clinical features of CS due to adrenal adenoma. Subsequently, an adrenal adenoma was detected in the contralateral adrenal gland in the mother 10 years after surgical treatment, when she presented with subclinical CS. To our knowledge, this is the first report to describe this rare form of familial CS.

\section{Case Reports}

\section{Case 1}

A 29-year-old woman, the daughter of patient 2 described below, complained to her family physician of progressive weight gain, having reached $10 \mathrm{~kg}$ over the previous three years. She had also noted hypertension and a change in her facial appearance during the past year. She was concerned since the condition resembled her mother's former symptoms, and her family physician referred her to our hospital for a further evaluation. On a physical examination, the patient was $162 \mathrm{~cm}$ tall and weighed $68.2 \mathrm{~kg}$. She exhibited several Cushingoid features, including a moon face, hirsutism, acne, buffalo hump and abdominal striae. Her blood

\footnotetext{
${ }^{1}$ Department of Metabolism and Endocrinology, Clinical Research Institute, National Hospital Organization Kyushu Medical Center, Japan and ${ }^{2}$ Division of Endocrinology and Metabolism, Clinical Research Institute National Hospital Organization Kyoto Medical Center, Japan Received for publication February 13, 2013; Accepted for publication November 24, 2013 Correspondence to Dr. Atsushi Ogo, aogo@kyumed.jp
} 
Table. Endocrinological Data of the Patients (Mother and Daughter)

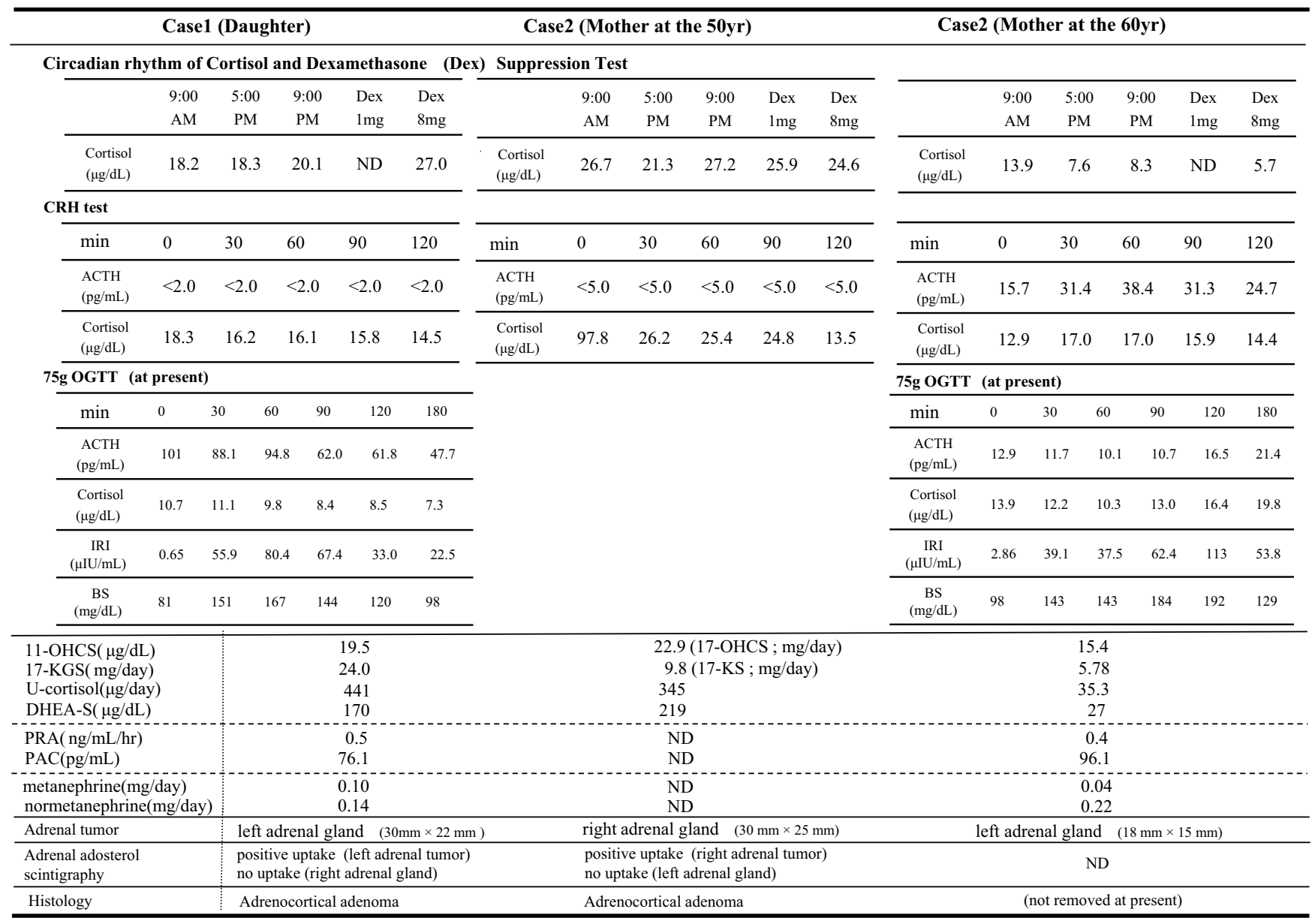

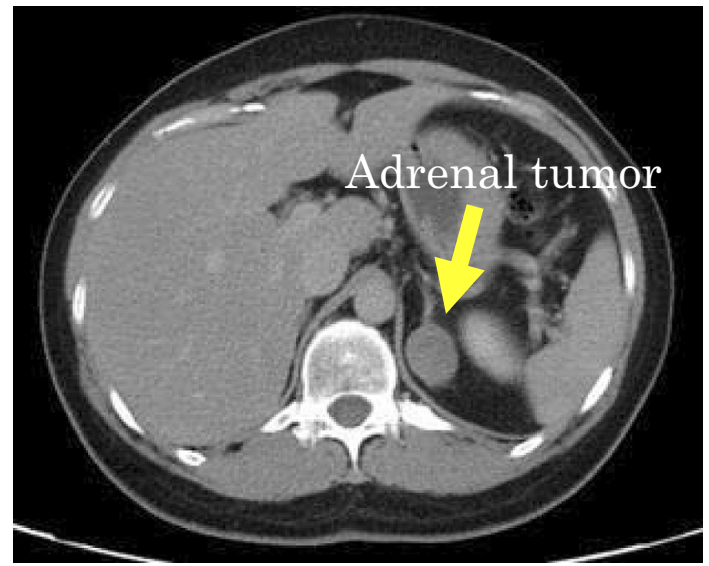

Figure 1. Abdominal CT scan shows of a hypodense, homogenous nodular mass in the left adrenal gland measuring $30 \times 22$ mm, with well-defined margins.

pressure was $172 / 102 \mathrm{mmHg}$. The results of a routine laboratory examination included a serum potassium level of 4.2 $\mathrm{mEq} / \mathrm{L}$ and a glucose level of $93 \mathrm{mg} / \mathrm{dL}$. An endocrine evaluation revealed (Table) the plasma ACTH level to be low (09:00 h, $<2.0 \mathrm{pg} / \mathrm{mL})$. Meanwhile, the cortisol level was elevated without maintenance of the circadian rhythm (09:00 h, 18.2 $\mu \mathrm{g} / \mathrm{dL} ; 17: 00 \mathrm{~h}, 16.2 \mu \mathrm{g} / \mathrm{dL} ; 21: 00 \mathrm{~h}, 20.1$ $\mu \mathrm{g} / \mathrm{dL})$; the plasma cortisol level was not completely sup- pressed by the overnight administration of $8 \mathrm{mg}$ of dexamethasone $(27.0 \mu \mathrm{g} / \mathrm{dL})$. The urinary excretion of free cortisol (441 $\mu \mathrm{g} / \mathrm{day})$, urinary 11-hydroxycorticosteroid (11OHCS: $19.5 \mu \mathrm{g} /$ day) and 17-ketogenic steroids (17-KGS: $24.0 \mathrm{mg}$ /day) was elevated. An abdominal computed tomography (CT) scan revealed a smooth, ovoid, well-defined nodular mass in the left adrenal gland measuring $30 \times 22 \mathrm{~mm}$ in size with low attenuation (Fig. 1). Axial in-phase and outof-phase adrenal magnetic resonance imaging (MRI) scans showed an oval-shaped tumor in the left adrenal gland with signal dropout, a finding suggestive of intracellular lipids, a characteristic feature of benign adenoma (Fig. 2). Adrenal scintigraphy using ${ }^{131}$ I-labeled adosterol revealed a positive uptake in the left adrenal tumor with no uptake in the right adrenal gland (Fig. 3). These findings indicated that the cortisol production in the adrenal tumor was not regulated by the hypothalamic-pituitary-adrenal axis.

The patient underwent left laparoscopic adrenalectomy, during which the surface of the tumor was found to be smooth and not adherent to the kidney. On the pathological examination, the maximal diameter of the left adrenal tumor was $30 \times 25 \mathrm{~mm}$. The lesion was well-demarcated, solid and yellowish-brown in color. The histological sections revealed the nodular proliferation of cells in the zona fasciculata of the adrenal cortex. Neither nuclear atypia nor mitotic figures were detected. The stroma consisted of sinusoidal vessels 

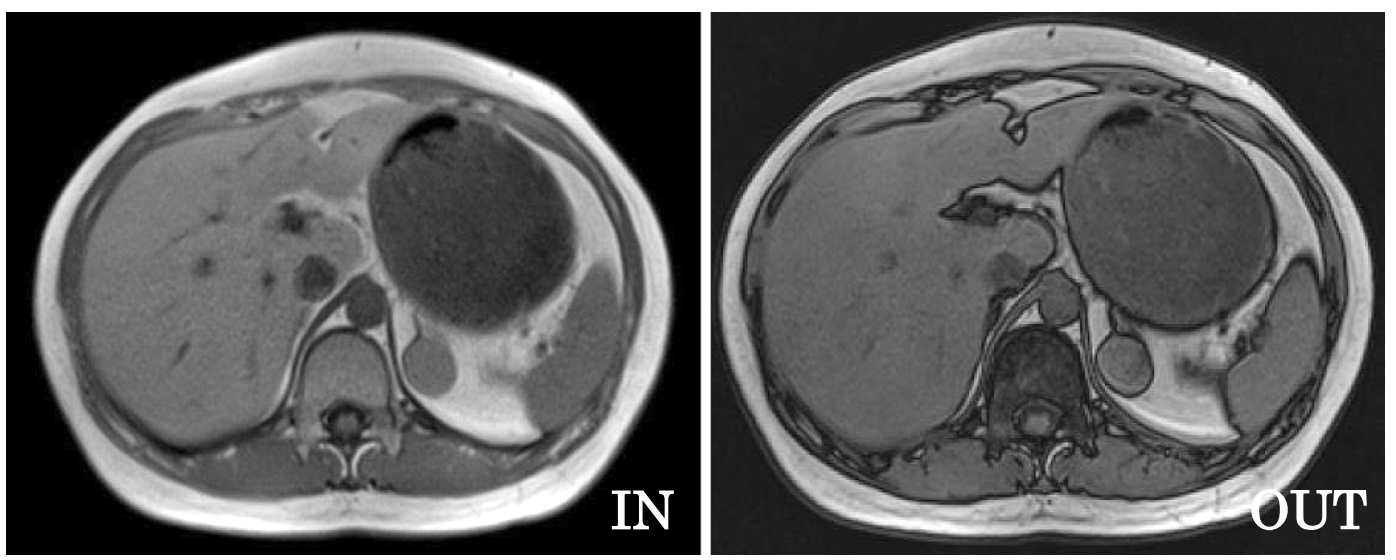

Figure 2. Axial in-phase and out-of-phase adrenal MRI scans show an oval-shaped tumor of the left adrenal gland with signal drop-out, a characteristic feature of benign adenoma.
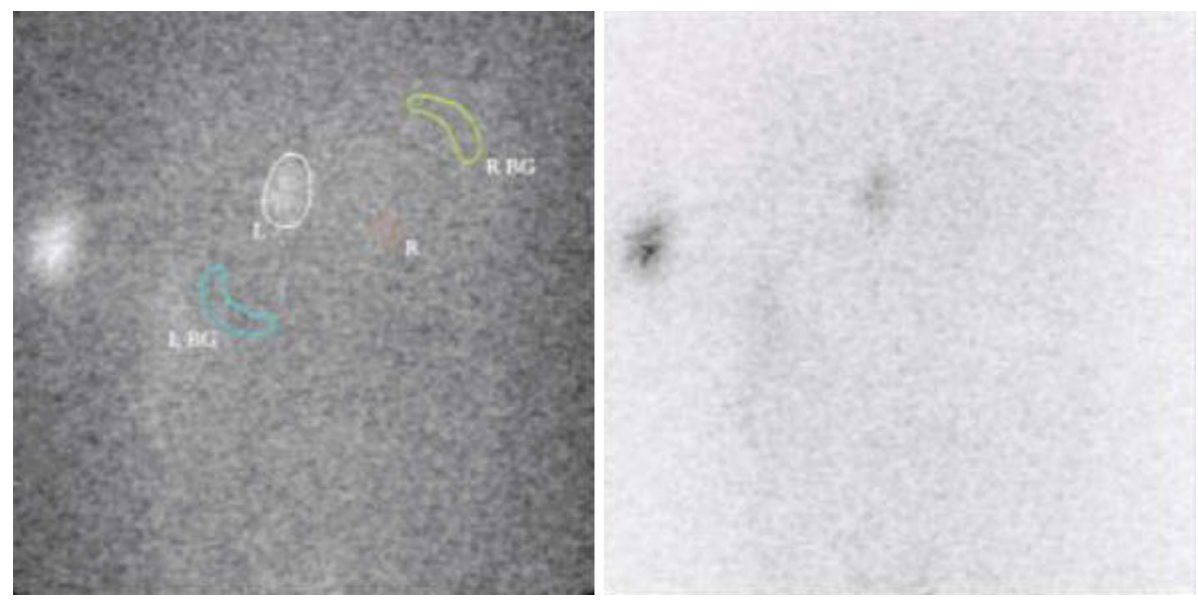

Figure 3. Adrenal scintigraphy using ${ }^{131}$ I-labeled adosterol revealed positive uptake in the left adrenal tumor with no uptake in the right adrenal gland.

(Fig. 4). Immunohistochemistry staining was positive for CYP11B1, 17 $\alpha$-hydroxylase and 3-ßhydroxysteroid dehydrogenase (HSD) (Fig. 5). An adrenal cortical adenoma producing cortisol was considered to be the most likely diagnosis.

The patient's clinical course was uneventful, and she was discharged on postoperative day 14. Hydrocortisone replacement therapy was continued for nine months after surgery. The administration of oral (75 g) glucose increased the patient's blood glucose and plasma insulin concentrations. In contrast, the oral administration of glucose induced no increases in the plasma cortisol level at that time (Table).

\section{Case 2}

A 50-year-old woman, the mother of patient 1 (the family pedigree is shown in Fig. 6), was hospitalized for a further evaluation of a right adrenal incidentaloma measuring $30 \times 25$ $\mathrm{mm}$ in 2002. The physical examination findings were notable for a Cushingoid appearance, including central obesity, moon face, hirsutism and buffalo hump. The initial laboratory results included a serum potassium level of $4.0 \mathrm{mEq} / \mathrm{L}$ and a glucose level of $112 \mathrm{mg} / \mathrm{dL}$. The serum cortisol level ranged from 21.3 to $27.2 \mu \mathrm{g} / \mathrm{dL}$, without diurnal variation. The ACTH level was less than $2 \mathrm{pg} / \mathrm{mL}$. A 24-hour urine collection specimen contained $345 \mu \mathrm{g} /$ day of free cortisol, $9.8 \mathrm{mg} /$ day of 17-ketosteroids and $22.9 \mathrm{mg} /$ day of $17-$ OHCS. Dynamic testing showed no suppression of free cortisol with high-dose dexamethasone (24.6 $\mu \mathrm{g} / \mathrm{dL})$ (Table). Abdominal CT scans showed a nodular mass in the right adrenal gland measuring $30 \times 25 \mathrm{~mm}$. The lesion was smooth, ovoid, well-defined, homogenous and exerted pressure on the inferior vena cava ((Fig. 7). Adrenal scintigraphy using ${ }^{131}$ I-labeled adosterol revealed a positive uptake in the right adrenal tumor with no uptake in the left adrenal gland (Fig. 8). Right adrenalectomy was performed.

The morphological findings indicated that the tumor was a demarcated round mass measuring $30 \times 25 \mathrm{~mm}$ without capsule formation. Histological sections of the tumor demonstrated the proliferation of eosinophilic round tumor cells exhibiting a medullary growth pattern with mild lipofuscin deposition (Fig. 9). Immunohistochemistry demonstrated positive staining of CYP11B1, 17 $\alpha$-hydroxylase and 3- 

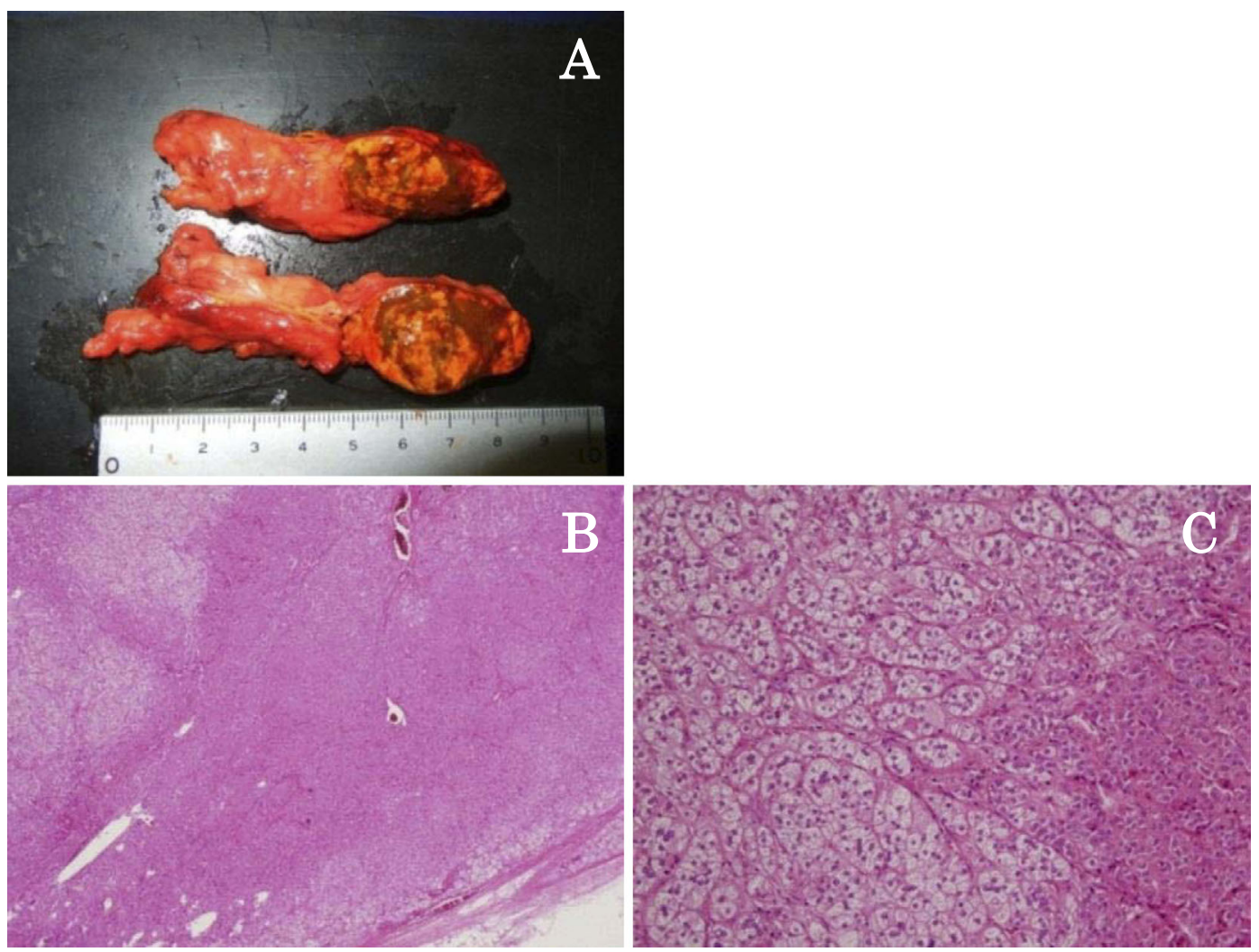

Figure 4. Macroscopic and microscopic appearances of the adrenal gland from the daughter. (A) Adrenal gland cross-sections. The tumor had a yellowish cut surface and was well-encapsulated without nodules in the surrounding tissue. Hematoxylin and Eosin staining of adrenal gland sections at low (B) and high-power (C) magnification ( $\times 2$ and 10). Histological examination revealed that the sections showed nodular proliferation of cells in the zona fasciculata of the adrenal cortex. Adrenal cortical adenoma was considered to be the most likely diagnosis.

\section{CYP11B1}

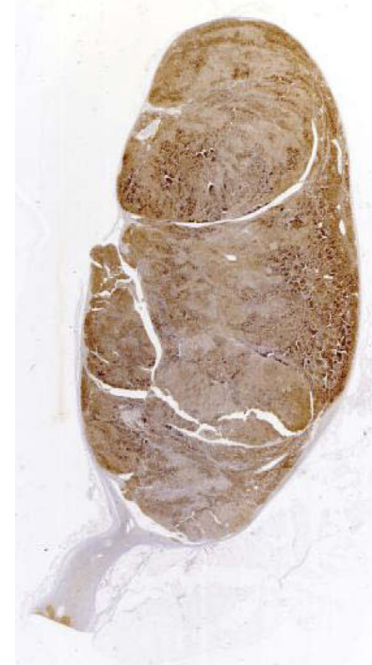

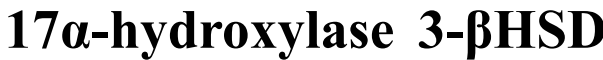

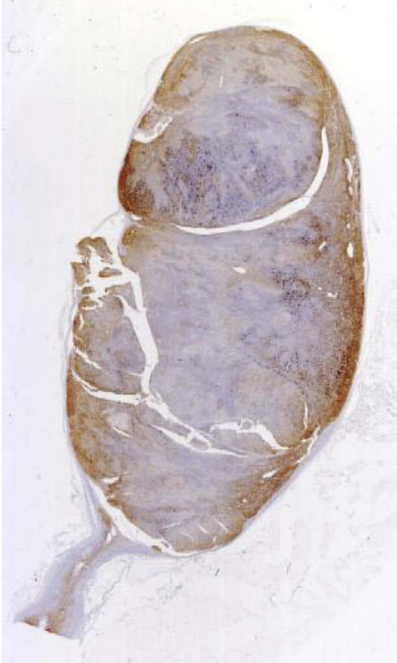

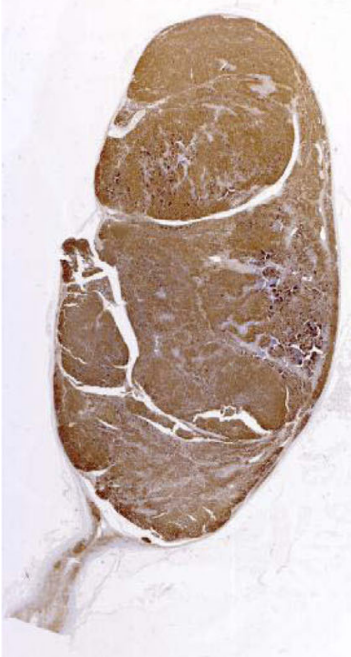

Figure 5. Immunohistochemistry showing a positive staining for, CYP11B1, 17 $\alpha$-hydroxylase and 3- $\beta$ HSD in the left adrenal tumor.

$\beta \mathrm{HSD}$ in the tumor, whereas the adjacent atrophic adrenal gland showed no immunoreactivity (Fig. 10).

An adrenocortical adenoma producing cortisol, compact cell type, was considered to be the most likely diagnosis. Hydrocortisone replacement therapy was continued for eight months after surgery, and the patient was subsequently fol- 


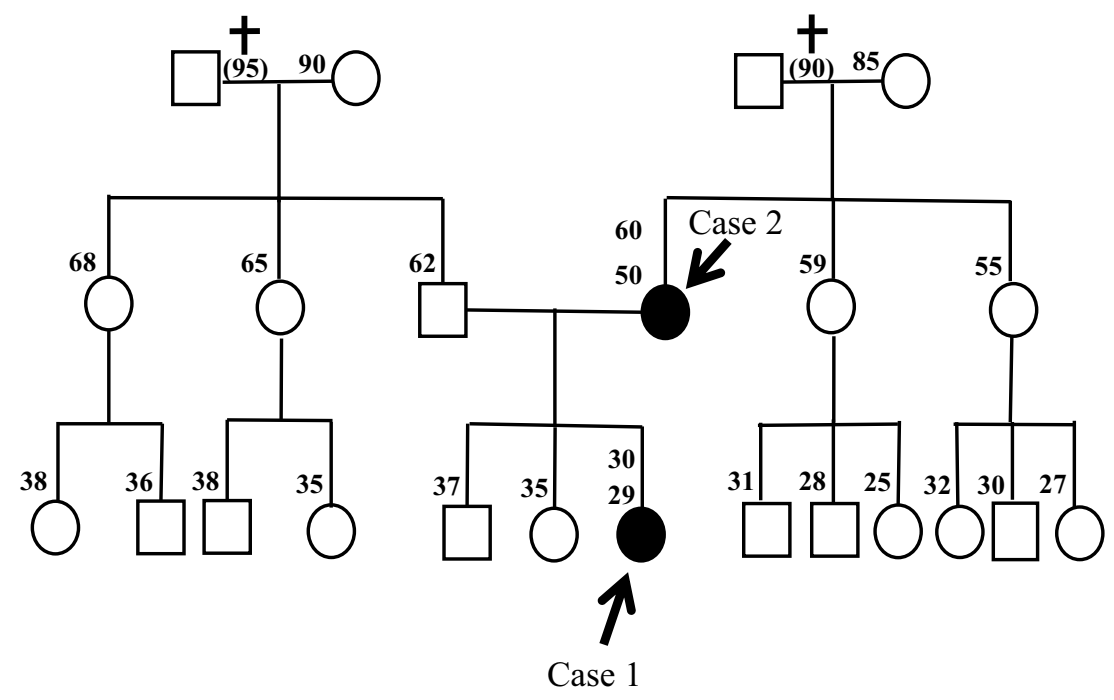

Figure 6. Pedigree of the family. Affected patients are shown as full black symbols. Unaffected patients are depicted as white symbols. Numbers is parenthesis indicated the age at the time of death, the present age is indicated at the left upper side of the corresponding symbol. The number on the left lower side of the symbol is the age at the time of operation. The arrow identifies the index patients.

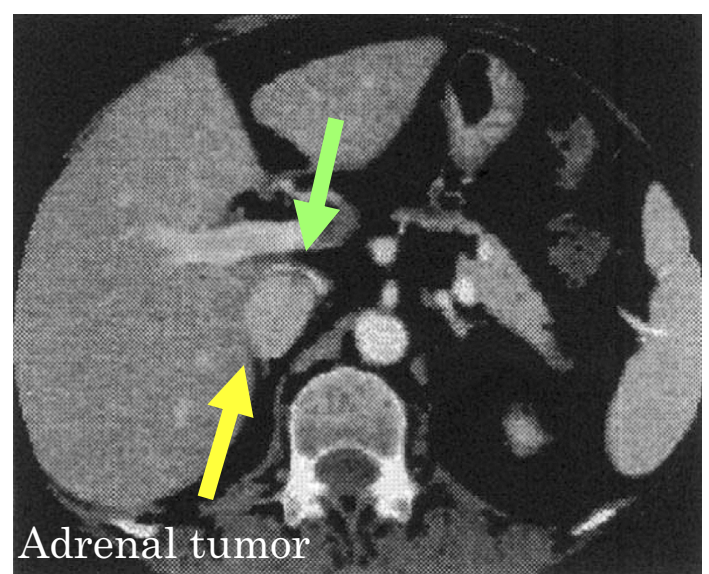

Figure 7. Abdominal CT shows a smooth, ovoid, well-defined, homogenous, nodular mass in the right adrenal gland measuring $30 \times 25 \mathrm{~mm}$, exerting pressure on the inferior vena cava.

lowed up by her family doctor.

After her daughter's surgery, i.e., 10 years after her adrenalectomy, a left adrenal incidentaloma measuring $18 \times$ $15 \mathrm{~mm}$ was detected on abdominal CT performed for dyspepsia, and the patient again consulted our hospital. She had no clinical signs or symptoms of hypercortisolism. An endocrine evaluation revealed (Table) the basal levels of plasma ACTH and cortisol to be normal $(13.5 \mathrm{pg} / \mathrm{mL}$ and $13.9 \mu \mathrm{g} /$ $\mathrm{dL}$, respectively). However, the nocturnal cortisol level was high (09:00 h, 13.9 $\mu \mathrm{g} / \mathrm{dL} ; 17: 00 \mathrm{~h}, 7.6 \mu \mathrm{g} / \mathrm{dL} ; 21: 00 \mathrm{~h}, 8.3$ $\mu \mathrm{g} / \mathrm{dL}$ ), and the plasma cortisol level was not completely suppressed by the overnight administration of $8 \mathrm{mg}$ of dexamethasone $(5.7 \mu \mathrm{g} / \mathrm{dL})$. The urinary excretion of free cortisol $(35.3 \mu \mathrm{g} /$ day $)$, urinary 11-OHCS (15.4 $\mu \mathrm{g} /$ day) and 17KGS $(5.78 \mathrm{mg} /$ day) was normal. Other endocrine data were

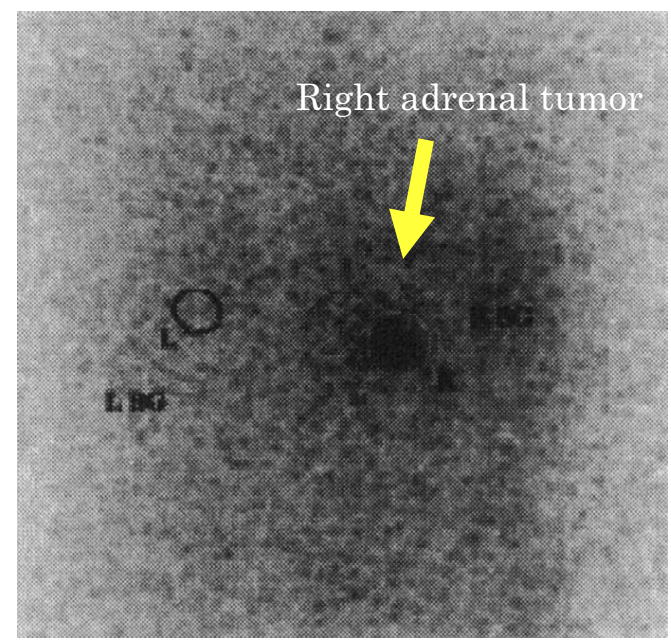

Figure 8. Adrenal scintigraphy using ${ }^{131}$ I-labeled adosterol revealed positive uptake in the right adrenal tumor with no uptake in the left adrenal gland.

as follows: plasma aldosterone, $96.1 \mathrm{pg} / \mathrm{mL}$; plasma renin activity (PRA), $0.4 \mathrm{ng} / \mathrm{mL} / \mathrm{h}$; plasma epinephrine, $9 \mathrm{pg} / \mathrm{mL}$; plasma norepinephrine, $238 \mathrm{pg} / \mathrm{mL}$; plasma dopamine, $<5$ $\mathrm{pg} / \mathrm{mL}$; urinary epinephrine, $3.7 \mu \mathrm{g} /$ day; urinary norepinephrine, $183.5 \mu \mathrm{g} /$ day; urinary metanephrine, $0.04 \mathrm{mg} /$ day; urinary normetanephrine, $0.22 \mathrm{mg} /$ day; urinary vanillylmandelic acid, $3.1 \mathrm{mg} /$ day; and urinary homovanillic acid, 3.4 $\mathrm{mg} /$ day. The administration of oral $(75 \mathrm{~g})$ glucose induced increases in the blood glucose and plasma insulin levels; however, the plasma cortisol level did not increase significantly following the administration of glucose. Abdominal CT scans revealed a nodular mass in the left adrenal gland measuring $18 \times 15 \mathrm{~mm}$ (Fig. 11). The lesion was hypodense, homogenous and exhibited rapid enhancement following the injection of intravenous contrast medium. Axial in-phase and 

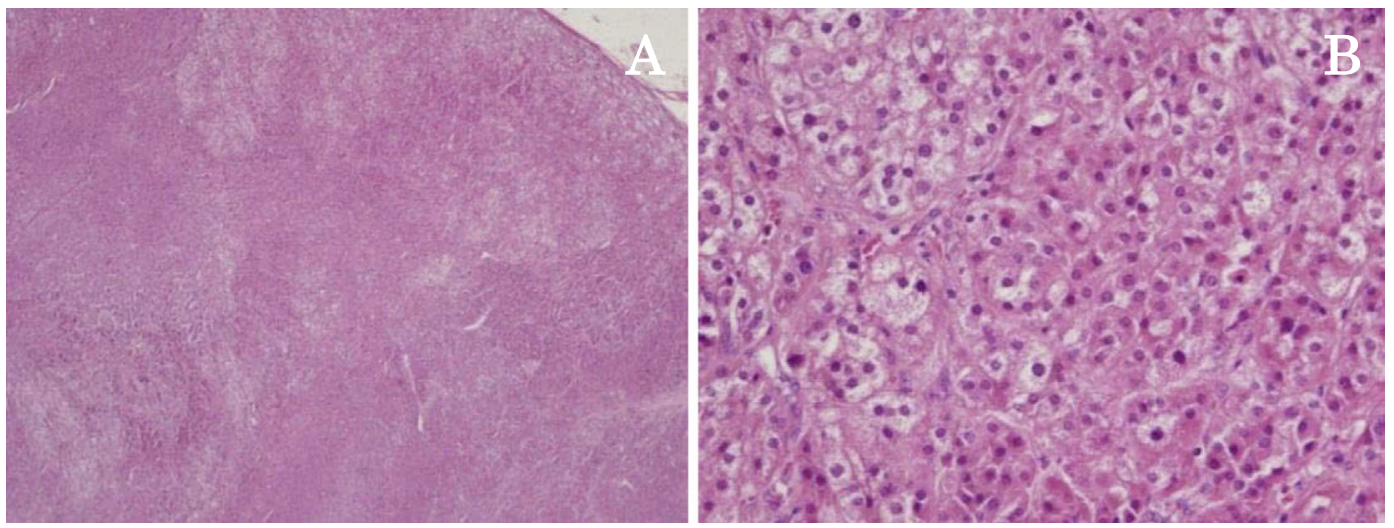

Figure 9. Microscopic appearances of the adrenal gland from the mother. Hematoxylin and Eosin staining of adrenal glands at low (A) and high-power (B) magnification ( $\times 2$ and 10). Sections show proliferation of eosinophilic round tumor cells forming a medullary growth pattern. Mild lipofuscin deposition is present in the tumor. Adrenal cortical adenoma, compact cell type, was considered to be the most likely diagnosis.
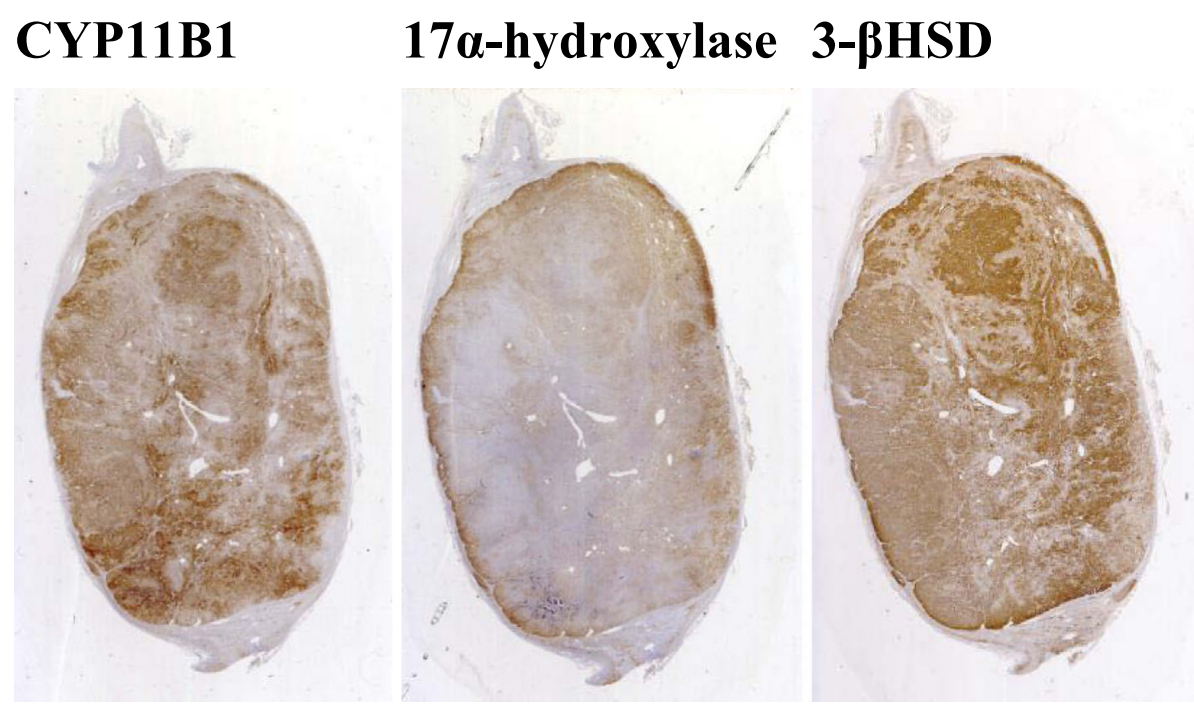

Figure 10. At the immunohistochemical investigation, the adrenal tumor cells were diffusely positive for CYP11B1, 17 $\alpha$-hydroxylase and 3- 3 HSD. Conversely, no immunoavtivity was found in the adjacent adrenal gland.

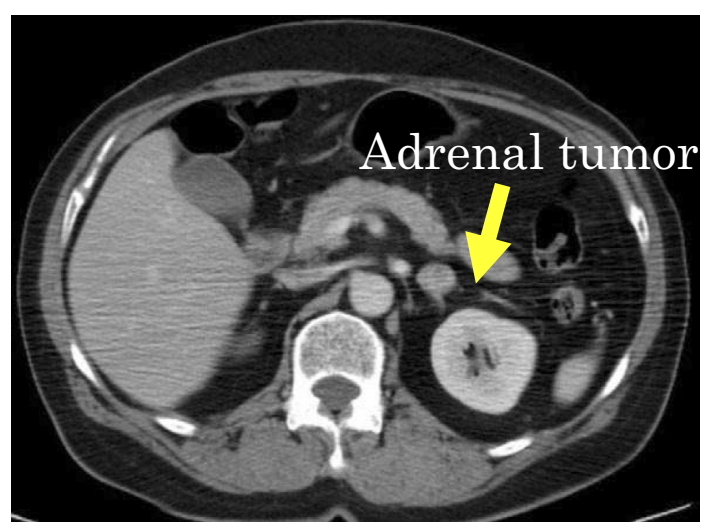

Figure 11. Abdominal CT scan shows a nodular mass in the left adrenal gland measuring $18 \times 15$ mm. The mass was hypodense, homogenous, and showed rapid enhancement after intravenous contrast medium injection. 

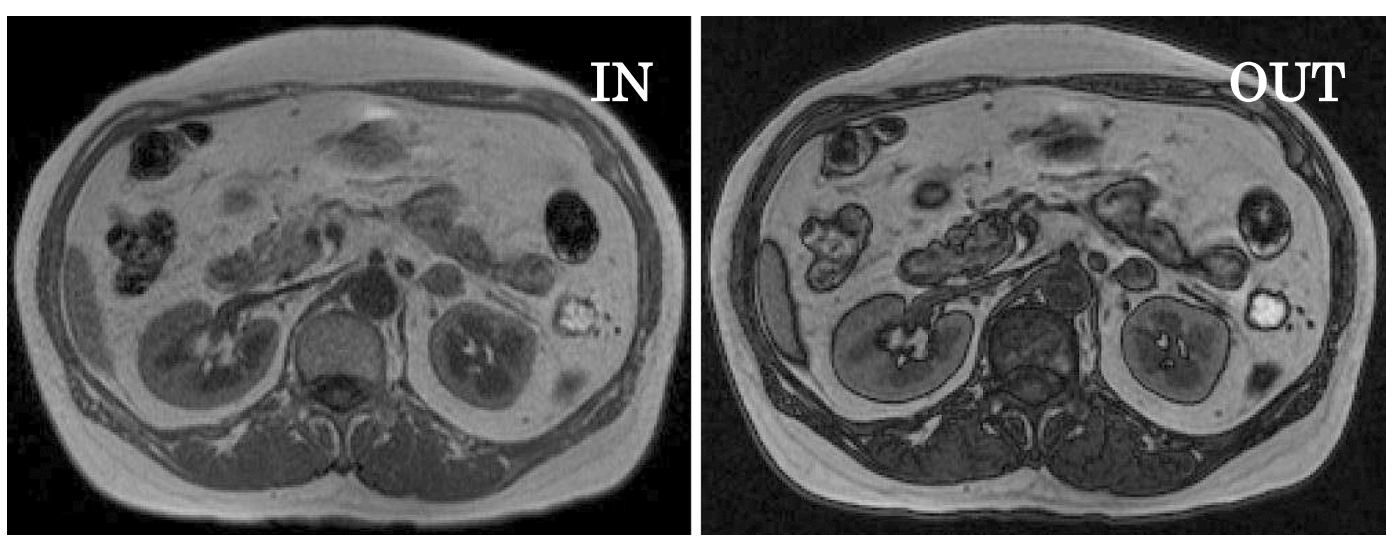

Figure 12. Axial in-phase and out-of-phase adrenal MR images show the left adrenal gland mass with classic signal drop-out, a characteristic feature of benign adenoma.

out-of-phase MR images showed the mass to display classic signal dropout (Fig. 12). These findings indicated that the tumor was an adenoma associated with subtle abnormalities of the hypothalamic-pituitary-adrenal axis. Since the patient had only one adrenal gland and there were no remarkable signs or symptoms of CS, she was closely followed without intervention.

\section{Discussion}

The initial step in the differential diagnosis of CS is to distinguish ACTH-dependent from ACTH-independent forms of hypercortisolism. ACTH dependency accounts for $80 \%$ of cases of CS. Of these cases, $85 \%$ involve ACTH-secreting pituitary adenomas, while $15 \%$ involve ectopic ACTHsecreting tumors (4). ACTH-independent hypercortisolism is always of adrenocortical origin. By far the most common cause ( $>95 \%$ of cases) is adrenocortical adenoma or carcinoma. Most remaining patients have primary pigmented nodular adrenal dysplasia (PPNAD), a syndrome characterized by the presence of multiple small bilateral pigmented adrenocortical nodules, often in association with the Carney complex $(5,6)$. The Carney complex presents in adolescence or young adulthood in patients with unusual conditions, such as myxomas with spotty skin pigmentation, endocrine overactivity or schwannomas. The adrenal glands in patients with this disorder are often small or normal in size with multiple black and brown nodules associated with intranodular cortical atrophy. An even rarer form of ACTHindependent primary adrenal hypercortisolism consists of multiple bilateral adrenocortical macronodules inducing the striking enlargement of the adrenal glands, called ACTHindependent macronodular adrenocortical hyperplasia (AIMAH) (7-11). The histological features of adrenal glands with AIMAH include multiple large nodules with interspersed markedly hyperplastic adrenal tissue between the nodules; there is no pigmentation.

The present patients, a mother and daughter, had ACTHindependent forms of hypercortisolism with single adrenal tumors on CT or MRI in addition to unilateral uptake on ad- renal scintigraphy. Histologically, the excised adrenal tumors were very similar, and both were adrenal adenomas. The tumor features in the mother and daughter included a compact cell type and demarcated round masses without capsule formation. Immunohistochemistry demonstrated that both adenomas produced cortisol.

Most often Cushing's disease occurs as a sporadic, isolated condition. Rarely, it can appear as a component of genetic syndromes, such as multiple endocrine neoplasia type 1 (MEN1), Carney complex (CNC) and micronodular adrenal disease. $M E N 1$ is a familial disorder that exhibits autosomal-dominant transmission due to an inactivating mutation in the MEN1 gene located in chromosome 11q13. Most adrenal tumors in patients with MEN1 are nonfunctional; however, a few cortisol-producing tumors have been reported (12). In the present cases, neither the daughter nor her mother had MEN1-related endocrine disorders, including hyperparathyroidism, the most frequently observed endocrine disorder in MEN1 patients. CNC is another genetic disorder that can cause Cushing's syndrome. Inactivating germline mutations in the gene coding for PRKARIA, a regulatory subunit of PKA, have been found $(13,14)$. The gene coding for PRKARIA is located on chromosome 17q22-23. All described mutations (small or large deletions, base substitutions, etc.) usually result in premature stop codons. It has been noted that such mutations can also induce the expression of abnormal proteins, thus demonstrating that alteration of the PRKARIA function augments the PKA activity, thereby leading to tumorigenesis in tissues affected by CNC. More than $60 \%$ of CNC patients harbor pathogenic PRKAR1A mutations. Other loci located on chromosome 2 (2p16, 2q31.2 regions) have been implicated in the tumorigenesis of CNC. Inactivating mutations in the phosphodiesterase 11A (PDE11A) gene, located on chromosome 2q31.2, have been described in patients with PPNAD negative for PRKARIA mutations (15). Inactivating mutations in $P D E 11 A$ result in the disruption of the ability to hydrolyze cAMP and cGMP. For example, a mutation in the gene coding for $P D E 8 B$ (locus 5q13) resulting in a disrupted ability to hydrolyze cAMP has been described (16). The gross and 
histological appearance of PPNAD is characteristic. The pathological findings of the present cases did not involve PPNAD characteristics, and we did not detect any other CNC-related disorders, such as skin pigmentation or cardiac myxoma. Based on these clinical and pathological observations, we concluded that genetic alterations of these known genes were unlikely to be present in these cases. Therefore, we did not perform any genetic testing.

Other genetic mutations responsible for several primary cortical disorders have been identified (17). A somatic mutation of TP53, a tumor suppressor gene (18), and a germline mutation of the adenomatous polyposis coli (APC) gene that result in the activation of the $\mathrm{Wnt} / \beta$-catenin signaling pathway also play important roles in cell proliferation and have been demonstrated in patients with adrenocortical tumors (19). Recently, aldosterone-producing adenoma (APA) was shown to possess somatic mutations (G151R and L168R) in KCNJ5 that cause alterations in channel selectivity leading to nonselective $\mathrm{Na}$ entry and chronic depolarization (20).

In addition, several hypotheses have been proposed in the literature $(17,21,22)$, including the presence of unknown non-ACTH adrenal growth factors or the expression of ectopic receptors for such substances, such as increased responsiveness to gastric inhibitory polypeptide receptors (food-dependent hypercortisolism), vasopressin receptors or $\beta$-adrenergic receptors and so on, that do not usually control the adrenal growth or function. Even if the plasma cortisol concentration did not increase significantly following the administration of oral glucose in either the mother or daughter, the examinations conducted after the removal of the adrenal adenomas detected overt Cushing's syndrome. The possibility that these pathological mechanisms may have played a role in the present cases cannot be completely excluded. As far as we were able to investigate, there were no endocrine disorders in relatives or consanguineous marriage, although the existence of an asymptomatic endocrine disease also cannot be completely excluded (Fig. 1). Therefore, the pathogenesis underlying these familial cases remains unclear, although the presence of unknown genetic abnormalities causing hereditary CS is suggested. Further genetic analyses of such familial cases are required.

In the literature, reported bilateral adrenocortical adenomas have usually been found simultaneously. However, in the present case 2, the right and left adrenocortical adenomas inducing the excess production of cortisol developed 10 years apart. Tung et al. (23) also reported bilateral adrenocortical adenomas causing ACTH-independent CS diagnosed nine years apart. Imai et al. (24) reported the results of long-term follow-up studies after adrenalectomy in 122 patients with CS. Of 70 patients with adrenocortical adenoma, CS recurred in two (2.9\%) cases due to the development of contralateral adrenocortical adenomas 20 years after the first adrenalectomy. These findings highlight the importance of providing regular follow-up in patients treated with unilateral adrenalectomy for adrenocortical adenoma.
To our knowledge, the present cases are the first reported familial cases of CS caused by adrenal adenoma. Furthermore, a second adrenocortical adenoma producing excess cortisol developed 10 years after the first lesion in the mother. Although the pathogenesis underlying these cases is currently poorly understood, further study is warranted, and close follow-up of both patients is required, focusing particularly on the possibility of tumor development in the other adrenal gland in the daughter and the presence of the clinical features of CS in the mother.

\section{The authors state that they have no Conflict of Interest (COI).}

\section{References}

1. Nies C, Bartsch DK, Ehlenz K, et al. Familial ACTH-independent Cushing's syndrome with bilateral macronodular adrenal hyperplasia clinically affecting only female family members. Exp Clin Endocrinol Diabetes 110: 277-283, 2002.

2. Watson TD, Patel SJ, Nardi PM. Familial adrenocorticotropinindependent macronodular adrenal hyperplasia causing Cushing syndrome1. Radiology 244: 923-926, 2007.

3. Carney JA, Gaillard RC, Bertherat J, Stratakis CA. Familial micronodular adrenocortical disease, Cushing syndrome, and mutations of the gene encoding phosphodiesterase 11A4 (PDE11A). Am J Surg Pathol 34: 547-555, 2010.

4. Nieman LK, Cutler GB Jr. Cushing's syndrome. In: Endocrinology. DeGroot LJ, Ed. Saunders, Philadelphia, 1995: 1741-1770.

5. Stratakis CA, Carney JA, Lin JP, et al. Carney complex, a familial multiple neoplasia and lentiginosis syndrome. Analysis of $11 \mathrm{kin}-$ dreds and linkage to the short arm of chromosome 2. J Clin Invest 97: 699-705, 1996.

6. Carney JA, Gordon H, Carpenter PC, Shenoy BV, Go VLM. The complex of myxomas, spotty pigmentation, and endocrine overactivity. Medicine 64: 270-283, 1985.

7. Malchoff CD, Rosa J, DeBold CR, et al. Adrenocorticotropinindependent bilateral macronodular adrenal hyperplasia: an unusual cause of Cushing syndrome. J Clin Endocrinol Metab 68: 855-860, 1989

8. Cheitlin RA, Westphal M, Cabrera CM, Fujii DK, Snyder J, Fitzgerald PA. Cushing's syndrome due to bilateral adrenal macronodular hyperplasia with undetectable ACTH: cell culture of adenoma cells on extracellular matrix. Horm Res 29: 162-167, 1988.

9. Findlay JC, Sheeler LR, Engeland WC, Aron DC. Familial adrenocorticotropin-independent Cushing's syndrome with bilateral macronodular adrenal hyperplasia. J Clin Endocrinol Metab 76: 189-191, 1993.

10. Terzolo M, Boccuzzi A, Ali A, et al. Cushing's syndrome due to ACTH-independent bilateral adrenocortical macronodular hyperplasia. J Endocrinol Invest 20: 270-275, 1997.

11. Swain JM, Grant CS, Schlinkert RT, et al. Corticotropinindependent macronodular adrenal hyperplasia: a clinicopathologic correlation. Arch Surg 133: 541-546, 1998.

12. Gaitan D, Loosen PT, Orth DN. Two patients with Cushing's disease in a kindred with multiple endocrine neoplasia type I. J Clin Endocrinol Metab 76: 1580-1582, 1993.

13. Casey M, Vaughan $\mathrm{CJ}$, He J, et al. Mutations in the protein kinase A R1 $\alpha$ regulatory subunit cause familial cardiac myxomas and Carney complex. J Clin Invest 106: R31-R38, 2000.

14. Kirschner LS, Carney JA, Pack SD, et al. Mutations of the gene encoding the protein kinase A type I- $\alpha$ regulatory subunit in patients with the Carney complex. Nat Genet 26: 89-92, 2000. 
15. Horvath A, Boikos S, Giatzakis C, et al. A genome-wide scan identifies mutations in the gene encoding phosphodiesterase $11 \mathrm{~A} 4$ $(P D E 11 A)$ in individuals with adrenocortical hyperplasia. Nat Genet 38: 794-800, 2006.

16. Horvath A, Giatzakis C, Tsang K, et al. A cAMP-specific phosphodiesterase (PDE8B) that is mutated in adrenal hyperplasia is expressed widely in human and mouse tissues: a novel PDE8B isoform in human adrenal cortex. Eur J Hum Genet 16: 12451253, 2008.

17. Yaneva M, Vandeva S, Zacharieva S, Daly AF, Beckers A. Genetics of Cushing's syndrome. Neuroendocrinology 92 (Suppl 1): 6$10,2010$.

18. Libè R, Groussin L, Tissier F, et al. Somatic TP53 mutations are relatively rare among adrenocortical cancers with the frequent 17p13 loss of heterozygosity. Clin Cancer Res 13: 844-850, 2007.

19. Tissier F, Cavard C, Groussin L, et al. Mutations of $\beta$-catenin in adrenocortical tumors: activation of the Wnt signaling pathway is a frequent event in both benign and malignant adrenocortical tumors. Cancer Res 65: 7622-7627, 2005.
20. Choi M, Scholl UI, Yue $\mathrm{P}$, et al. $\mathrm{K}^{+}$channel mutations in adrenal aldosterone-producing adenomas and hereditary hypertension. Science 331: 768-772, 2011.

21. Nakamura Y, Son Y, Kohno Y, et al. Case of adrenocorticotropic hormone-independent macronodular adrenal hyperplasia with possible adrenal hypersensitivity to angiotensin II. Endocrine 15: 5761, 2001.

22. Lacroix A, Ndiaye N, Tremblay J, Hamet P. Ectopic and abnormal hormone receptors in adrenal Cushing's syndrome. Endocr Rev 22: 75-110, 2001.

23. Tung SC, Wang PW, Huang TL, Lee WC, Chen WJ. Bilateral adrenocortical adenomas causing ACTH-independent Cushing's syndrome at different periods: a case report and discussion of corticosteroid replacement therapy following bilateral adrenalectomy. J Endocrinol Invest 27: 375-379, 2004.

24. Imai T, Funahashi H, Tanaka Y, et al. Adrenalectomy for treatment of Cushing syndrome: results in 122 patients and long-term follow-up studies. World J Surg 20: 781-787, 1996.

(C) 2014 The Japanese Society of Internal Medicine http://www.naika.or.jp/imonline/index.html 